\title{
Tongmenghui 同盟会 y Zhigongtang 致公党. El proyecto de República de Sun Yatsen y los chinos de ultramar (1894-1911)
}

\author{
Tonatiuh Fierro de Jesús \\ Licenciatura en Relaciones Internacionales, Universidad Nacional Autónoma de México, 2011. Maestría \\ en Estudios de Asia y África, Especialidad China, El Colegio de México, 2015. \\ Correo electrónico: tfierro@colmex.mx
}

Fecha de recibido: 25 de enero de 2015 - Fecha de aceptación: 17 de febrero de 2015

\author{
Palabras clave \\ Redes fraternales, chinos de ultramar, Sun Yatsen, Tongmenghui, Zhigongtang
}

\author{
Keywords \\ Fraternal networks, overseas Chinese, Sun Yat-sen, Tongmenghui, Zhigongtang
}

\begin{abstract}
Resumen
Este artículo analiza la promoción del proyecto de República de Sun Yatsen en las redes fraternales de chinos de ultramar entre 1894 y 1911. En este sentido, se analizan dos casos: el Tongmenghui 同盟会 en Asia y el Zhigongtang 致公党 en Estados Unidos, Canadá y algunos países de Latinoamérica. Estos casos demuestran la relevancia económica y política de los chinos de ultramar en el proceso de construcción del nacionalismo y la ciudadanía chinos, así como el dinamismo forjado en la organización de los chinos en el exterior en defensa de sus propios intereses. Por lo tanto, el objetivo de este trabajo es dilucidar el apoyo financiero y político, y las posibilidades reales que tuvo Sun Yatsen para el establecimiento de la República mediante la cooperación de las redes fraternales asociativas.
\end{abstract}

\begin{abstract}
This article analyzes the development of the Republic's project of Sun Yat-sen in overseas Chinese fraternal networks between 1894 and 1911. In this regard, two cases are analyzed: Tongmenghui 同盟会 in Asia and Zhigongtang 致公党 in the United States, Canada and some Latin American countries. These cases demonstrate the economic and political importance of overseas Chinese in the process of constructing Chinese nationalism and citizenship, as well as dynamism forged by the organization of overseas Chinese in defense of their own interests. Therefore, the aim of this study is to determine the extent of financial and political support, and the real possibilities that had Sun Yat-sen for the establishment of the Republic through the cooperation of fraternal associative networks.
\end{abstract}

“海外中国人是革命之母亲”, 孙中山 “Los chinos de ultramar son la madre de la Revolución”, Sun Yatsen

\section{Introducción}

El proceso de llegada de la modernidad a China implicó transformaciones en todas las esferas. En el mundo de las ideas, para el cambio de siglo (XIX-XX), el 
liberalismo experimentó una fuerte inserción, situación que los conservadores confucianos percibieron como una amenaza para el país ${ }^{1}$. Sin embargo, debido a la decadencia imperial, surgieron intelectuales militantes de las ideas liberales como Liang Qichao 梁啟超 (1873-1929) y Sun Yatsen 孙逸仙 (1866-1925). Este último pasó de exiliado político a ser el primer presidente de la República durante un proceso en el que buscó la ayuda de sus compatriotas en el exterior mediante una política nacionalista activa.

Acerca de lo anterior, Jacques Gernet explica que a Sun Yatsen se le debe reconocer más por la forma en qué buscó los subsidios y los apoyos en el exterior que por sus doctrinas republicanas ${ }^{2}$, lo cual podría ser, pero teniendo el cuidado de considerarlo tan sólo como un "grano de sal". La promoción activa del programa republicano de Sun entre los chinos de ultramar fue una respuesta a la ineficacia de la dinastía Qing para hacer frente a la desestabilización interna debido a las rebeliones, los desastres naturales, las hambrunas y la expansión del imperialismo. Ante estas circunstancias, Sun proponía construir una nación fuerte, para ello requería el apoyo financiero de los chinos de ultramar. Este proyecto, le ofrecía dar soluciones a la comunidad china, tanto al interior como al exterior del país. De este modo, los chinos en el exterior se organizaron mediante redes fraternales asociativas para impulsar y ayudar al programa revolucionario.

En este sentido, la ayuda financiera de los chinos de ultramar a Sun Yatsen no fue una simple respuesta a su proyecto nacional, como tampoco los fueron los múltiples viajes de Sun al exterior. Este proceso republicano implicó tomar posiciones frente al resto de la comunidad internacional para sostener la soberanía y la autodeterminación del país. En esta etapa histórica por primera vez en la historia de China, aparecen las comunidades de ultramar organizadas y con mayor interés en las cuestiones políticas de su país. La relación creada entre Sun y los chinos de ultramar permite observar elementos sobre la función emergente que desempeñó esta comunidad y su inclusión en el proyecto político de Sun. Por lo tanto, el objetivo principal de este trabajo consiste en analizar el uso de las redes fraternales asociativas de chinos de ultramar por parte de Sun en la promoción de su proyecto de República.

En esta exploración general, interesa resaltar la interacción de los chinos de ultramar con el movimiento republicano de Sun. Varios de ellos optaron por acercarse al programa revolucionario y de esa forma lograr objetivos en conjunto -activos-; otros prefirieron adoptar una posición escéptica -pasivos-, como los chinos en Europa, quienes participaron en menor medida, comparado con los chinos en Estados Unidos.

La estructura de este trabajo se divide en dos partes. La primera corresponde al período 1894-1905, donde se explican las causas que llevaron a Sun a buscar a los

\footnotetext{
${ }^{1}$ Albert Feuerwerker, "Aspects of the Transition from Qing to Republican China", Republican China X, no. 2 (1985): 1-22. Esteban Sánchez Solano, "China y su primera experiencia en la modernidad política (1911-1927)", en Estudios sobre China desde Latinoamérica: Geopolítica, Religión e Inmigración, eds. Susan Chen Mok, Jorge Bartels Villanueva, Ricardo Martínez Esquivel (San José, Costa Rica: SIEDIN Universidad de Costa Rica, 2013), 77-105.

${ }^{2}$ Jacques Gernet, El Mundo Chino, trad.: Dolors Folch (Barcelona, Editorial Crítica, 2005), 551.
} 
chinos de ultramar por medio de las asociaciones fraternales. En la segunda parte, se analiza el periodo 1905-1911, momento de la creación del Tongmenghui 同盟会, sociedad que reflejó una base revolucionaria más sólida y la ayuda del Zhigongtang 致 公堂 en los Estados Unidos. Estas organizaciones permitieron a Sun implementar nuevas estrategias para la recaudación de fondos.

\section{Primera etapa: 1894-1905}

Desde mediados del siglo XIX, la ola de emigración china se intensificó por varias vicisitudes. La falta de una política para revitalizar el comercio, la creciente competencia de las mercancías extranjeras con las chinas y la tecnología que se integró en las empresas -como la de hilados- hicieron que el comercio chino se debilitara aún más. La mayoría de ellos emigró como mano de obra barata o "culíes" para trabajos por lo general pesados, sin respeto su integridad física y moral, como en las minas o los proyectos ferroviarios. Para finales del siglo XIX, las segundas generaciones de estos emigrantes, se habían insertado en la dinámica económica local. Algunos, tuvieron la habilidad de crear tiendas, de convertirse en comerciantes o en ganaderos, y así lograr el éxito económico. En este sentido, los chinos de ultramar en Japón, Hawái, el Sudeste de Asia, Australia, Estados Unidos y Canadá se organizaron en redes fraternal asociativas como la Sociedad de la Triada en Singapur o el Zhigongtang en los Estados Unidos. Estas organizaciones tuvieron el objetivo de integrar socialmente al emigrante chino y combatir la violencia y la xenofobia consecuente del éxito económico de muchos ellos. También hubo una minoría de las élites políticas e intelectuales chinas, cuyos motivos de emigración versaron en formarse en nuevas ideas, por lo general en Europa y Estados Unidos $^{3}$.

A finales del siglo XIX, la guerra sino-japonesa (1894-1895) influyó en la vida social y política de China. El avance de la modernización japonesa durante la era Meiji, sería tomado como modelo por los chinos reformistas. En este entorno, Sun Yatsen tuvo en cuenta que el Imperio Qing ya no tenía el poder suficiente para restablecer el orden. Como consecuencia, Sun y sus asociados conformaron la primera acción política independiente, formando una organización revolucionaria clandestina conocida como la Sociedad para la Regeneración de China Xingzhonghui 兴中会 ${ }^{4}$. De hecho, los primeros proto-partidos políticos chinos aparecerían de manera secreta y conspirativa desde que Sun estableciera las ramas del Xingzhonghui en Honolulu y Hong Kong entre 1894 y $1895^{5}$. Es necesario aclarar, que estas asociaciones estaban prohibidas en territorio

\footnotetext{
${ }^{3}$ Chow Tse-tung, The May 4th Movement: Intellectual Revolution in Modern China (Harvard East Asian) (Cambridge, MA: Harvard University Press, 1960), 19-40.

${ }^{4}$ S. L Tikhvinsky, Modern History of China, trad.: Vic Schneierson (Moscow: Progress publishers, 1983), 362.

${ }^{5}$ Ernest P. Young, "Politics in the aftermath of revolution: the era of Yuan Shih-k'ai, 1912-1916", en The Cambridge History of China, ed. J. King Fairbank (Cambridge, Cambridge University Press, 1980), vol. 12 , part 1.
} 
chino porque representaban una amenaza al orden político existente y no contaban con recursos suficientes para realizar sus acciones. Las principales provincias donde se movilizaron fueron Guangdong y Fujian.

La experiencia de Sun con los levantamientos campesinos contra los manchúes, lo llevaron a integrarse a las primeras sociedades secretas revolucionarias y ser influenciado por sus normas, como el espíritu de camaradería, la asistencia mutua, la devoción y el sacrificio ${ }^{6}$. Al poco tiempo, Sun sería el principal responsable de la fundación de las primeras organizaciones abiertamente revolucionarias de China. Gracias a sus vínculos con el extranjero, el espacio portuario de China -en particular Hong Kong y Shanghái- y las comunidades chinas en los Estados Unidos, Japón y el Sudeste Asiático, los chinos de ultramar y los extranjeros serían los principales socios y simpatizantes del proyecto de $\operatorname{Sun}^{7}$. La élite educada de China con tendencia liberal entró a la participación política pero se mostró escéptica y limitada debido a las sanciones que había en contra de las organizaciones conspiradoras durante la dinastía Qing. A su vez, la élite educada no liberal creía que el Imperio y el orden confuciano debía continuar.

Ante la situación hostil en la que se encontraba el movimiento revolucionario, Sun corría el peligro de ser arrestado en China. Debido a esto, Sun se estableció en Hawái. En Honolulu, Sun tenía contactos con gran parte de la comunidad china y empezó la campaña contra los manchúes. Para 1894, en una reunión secreta, el Sun inauguró la primera sociedad moderna revolucionaria, el Xingzhonghui, integrada por comerciantes, empleados de oficinas y asistentes de tiendas. Algunos miembros provenían de los chinos más prósperos de ultramar, propietarios de grandes fincas, ganaderos y gerentes de empresas financieras. La declaración del Xingzhonghui-escrita por Sun- hizo énfasis en el patriotismo y el futuro negativo de China si seguía bajo el control manchú. La sociedad hizo un llamado a la organización de los chinos que estuvieran en el país, así como los que residieran en el extranjero para reactivar a China ${ }^{8}$. Esta agrupación se concentró en la recaudación de fondos y el reclutamiento de personas que estaban dispuestas a ir a China para participar en las acciones contra el Imperio. Con el establecimiento de esta sociedad en Hawái, se abría la posibilidad de trasladar el proyecto revolucionario al exterior, y que desde ahí se reconociera su legitimidad entre los chinos de ultramar. Los revolucionarios aprovecharon la coyuntura para poner énfasis en las comunidades chinas en el extranjero como resultado inicial de su exilio en el exterior y la necesidad de buscar ayuda financiera. Esta política causal con el tiempo sería activa.

No obstante, Sun Yatsen no fue a Hawái sólo para inducir el fervor revolucionario, también lo hizo para obtener apoyo para su proyecto político. Sun destacó que la dinastía Qing tenía que ser destruida, para así construir una sobre sus

\footnotetext{
${ }^{6}$ Tikhvinsky. Modern History, 360.

${ }^{7}$ Michael Gasster, "The republican revolutionary movement", en The Cambridge History of China, ed. J. King Fairbank (Cambridge, Cambridge University Press, 1980), vol. 11, part 2, 465-466.

${ }^{8}$ Tikhvinsky. Modern History, 362-363.
} 
ruinas. Para ello el apoyo financiero de la comunidad china era urgentemente necesario, a cambio hubo la promesa de "un buen gobierno"9. Después de lograr el triunfo de la revolución, China se volvería a ser la gran nación que siempre fue, se hablaba de su reavivamiento. La comunidad china en Hawái le brindó ayuda financiera, pero no era lo suficientemente grande para conseguir sus fines. Entonces, los esfuerzos revolucionarios para obtener ayuda se tuvieron que desplegar a otros territorios, tal fue el caso de Hong Kong, que estaba bajo el control británico.

Precisamente, por esta falta de ayuda, en enero de 1895, Sun se trasladó a Hong Kong y fundó otra rama de la sociedad. El programa político era similar al que se estableció en Hawái, nuevamente se hizo hincapié en la amenaza extranjera a China y la incapacidad de la dinastía para hacer frente a las potencias. Sin embargo, las sociedades secretas de Hawái y Hong Kong eran pequeñas y débiles. La insuficiencia de fondos era una constante. Al igual que en Hawái, los miembros provenían de Guangdong, y aproximadamente dos tercios de ellos vivían fuera de la propia China; su contacto con sus 400 millones de compatriotas se limitaba casi exclusivamente a las relaciones de parentesco y a los lazos con las sociedades secretas. La composición social del Xingzhonghui, por lo general provino de los sectores bajos de la sociedad, en su mayoría trabajadores errantes, campesinos desarraigados, soldados dados de baja, bandidos, piratas, ladrones y contrabandistas. También hubo eruditos que habían reprobado los exámenes de la función pública, algunos nobles y comerciantes ${ }^{10}$. Fue así que las sociedades secretas se fueron perfilando en esta época, y las pequeñas revueltas se hicieron más frecuentes.

En efecto, durante los primeros años, la política activa de Sun y sus seguidores se basaron en la búsqueda de financiamiento y solidaridad a su proyecto de Nación mediante el discurso patriótico de la responsabilidad que tenían los chinos de ultramar con su tierra. A pesar de que estas asociaciones obtenían el apoyo de sus connacionales, no conseguían un compromiso mayor ante el panorama desolador del país. Tampoco hubo una revisión a profundidad de los métodos y los procedimientos para la recaudación de dinero o un proyecto político integral para mejorar la vida de esta comunidad que salió huyendo de su "madre patria".

El hecho de que estas sociedades se hayan expandido en otros países, no significó la ausencia de avatares. Los revolucionarios ampliaron las ramas de las sociedades en Japón y Hawái, pero tuvieron poco éxito. La propaganda revolucionaria tuvo poca respuesta de los chinos de ultramar. La célula de la sociedad del Xingzhonghui creada en 1895 por Yang Quyun 楊飛鴻 (1861-1901) en Johannesburgo, Sudáfrica, no alteró el panorama desolador ${ }^{11}$. El llamado de Sun Yatsen para la ayuda

\footnotetext{
${ }^{9}$ Allen. F. Damon, "Financing Revolution: Sun Yat-sen and the Overthrow of the Ch'ing Dynasty", The Hawaiian Journal of History 25 (1991): 162.

${ }^{10}$ Gasster, "The republican", 466-468.

${ }^{11}$ En 1895, Yan Quyun se instaló en África después de haber huido de China a raíz del primer levantamiento fallido de Sun Yatsen.
} 
financiera entre los chinos en los Estados Unidos -entre junio y agosto de 1896-, tampoco dio resultados ${ }^{12}$.

Pese a la propagación de estas sociedades, Sun continuó con los mismos métodos que adoptó cuando formó el Xingzhonghui. Las cuotas eran la primera fuente de dinero. Las cuotas de admisión y anuales, además de la "donación especial", se esperaban de todos los miembros de las sociedades. Las cantidades y los métodos de recolección variaron, pero el sentido de compromiso individual era aceptado por la mayoría de los miembros ${ }^{13}$. La recurrencia a los chinos de ultramar significó un medio para lograr el financiamiento. Con esta contribución a la revolución, tenemos así el primer nexo que se pone en movimiento de esta comunidad al cambio político de su país. El sentido de intuición de Sun fue muy alto para percibir que su propia comunidad le ayudaría en la necesidad de transformar a China para dar soluciones a los problemas urgentes por los que pasaba el país, y por las cuales huyeron de ahí: la miseria.

El cambio de siglo (XIX-XX) presagiaba cambios políticos, jurídicos, económicos, culturales y tecnológicos aún más profundos en el nuevo orden global. En China, el escenario político se preparaba para la aparición protagónica de los revolucionarios y para los chinos de ultramar, a quienes debido a su participación en el proyecto republicano, se les quitaría el estigma de ser ciudadanos de segunda. A fin de siglo XIX, Hong Kong, Hawái y Japón fueron las fuentes principales de fondos. Ya para 1905, con la creación de la Liga Unida Tongmenghui 同盟会, que integró a varios grupos revolucionarios chinos como el Xingzhonghui 兴中会 y la Restauración para la Sociedad Guangfuhui 光复会, el apoyo financiero aumentó. En aquel año, Sun Yatsen buscó el apoyo financiero en las comunidades chinas del Sudeste Asiático. Los emigrantes chinos eran en su mayoría de Guangdong y Fujian. Generalmente, se integraron en las instituciones que organizaron las fraternidades de ultramar chinas como las asociaciones de beneficencia y los albergues de la sociedad Hongmen 洪门 ${ }^{14} \mathrm{O}$ también conocida como Tiandihui 天地会 ${ }^{15}$. En 1904, Sun Yatsen se unió a esta última sociedad con el fin de obtener acceso a sus miembros y ayuda monetaria ${ }^{16}$.

Durante el siglo XIX, más de 20 millones de chinos emigraron al extranjero. Muchos de los primeros de estos emigrantes trabajaron como "culíes" en las zonas mineras, en particular de yacimientos de oro, en las obras de construcción de carreteras, plantaciones y pastizales, principalmente en el Sudeste de Asia, América, Australia y Nueva Zelanda. En el caso de Australia, la campaña de propaganda revolucionaria animó a los miembros del Hongmen a expresar su sentimiento antimanchú. Se dieron

\footnotetext{
${ }^{12}$ Tikhvinsky. Modern History, 368.

${ }^{13}$ Damon. "Financing Revolution", 170.

${ }^{14}$ Durante el siglo XIX, las ramas del Hongmen se formaron por chinos de ultramar, principalmente en Estados Unidos, Canadá y Australia. Su objetivo era apoyar a las comunidades chinas al exterior, incluso construyendo centros de beneficencia, y derrocar al régimen manchú, pero después del establecimiento de la República en 1911, sus miembros se dirigieron hacia actividades ilegales.

${ }^{15}$ Dian Murray y Qin Baoqi, The Origins of the Tiandihui. The Chinese Triads in Legend and History (Stanford, CA: Stanford University Press, 1994).

${ }^{16}$ C. Martin Wilbur, Sun Yat-sen: Frustrated patriot (Nueva York: Columbia University Press, 1976), 41.
} 
cuenta de la necesidad de fortalecer la relación entre ellos y el futuro de su patria, e hicieron más consciencia de una participación sociopolítica en las actividades de su país de origen. Esto ocurrió en dos vertientes. Primero, inició una campaña en contra de la "Australia blanca" y se solicitó el establecimiento de un consulado chino en Australia. Segundo, apoyaron el programa revolucionario de Sun Yatsen para el derrocamiento de la dinastía Qing y el establecimiento de una república. En éste, se establecería una Liga de Jóvenes chinos para recaudar fondos para la causa revolucionaria. Para 1911, se recaudó una suma de $£ 1300$, enviadas con un emisario a Sun ${ }^{17}$. Se destaca que la comunidad de chinos en Australia y el Pacífico Sur era poca a diferencia de la presenta en Hawái y los Estados Unidos en general, pero muy importante en la recaudación financiera que contribuyó para el impulso de la revolución. La intensificación de la inmigración china formaba parte tanto de la situación interna desestabilizadora como de la construcción hacia un nuevo orden global, en el cual las potencias exigían mayores estándares democráticos hacia estos países para su integración al escenario internacional.

En Sun, existía la voluntad de incorporar a China a esa realidad insoslayable que era la interdependencia comercial y la política internacional. Era difícil en ese contexto intentar hacer de China un Estado-Nación moderno, pero se aceptaba la idea de crear las condiciones necesarias para serlo y llegar a acuerdos con las potencias, siempre y cuando se entrelazarán el concepto de soberanía china y la apertura hacia su modernización; y sobre ellas insertarse en la dinámica global. La falta de consenso político entre los revolucionarios, los reformadores y la élite china obstaculizaron el camino. El tejido social estaba fracturado y la economía estancada, sin el desarrollo tecnológico adecuado para competir en el extranjero.

En 1897, la simpatía de Sun Yatsen le ayudó a recaudar dinero entre los chinos de ultramar en Canadá cuando se encontraba de regreso a Japón. Gracias a un grupo de japoneses aventureros expansionistas, Sun conoció a prominentes políticos japoneses y llegó a pensar en Japón como un "aliado natural" de China ${ }^{18}$. En Japón, reorganizó el programa revolucionario y obtuvo apoyo de un sinnúmero de benefactores. Eso permitió a Japón convertirse en la base principal de sus operaciones, donde residió seis años $^{19}$. En estos últimos años del siglo XIX y principios del XX, Japón emergió como el centro intelectual asiático y de la energía política e intelectual de Asia, donde se reclutaba a los exiliados políticos asiáticos, tanto chinos como filipinos, por lo que terminó autorepresentándose como el defensor de la "raza amarilla" en contra de la discriminación que padecían los pueblos asiáticos. Japón no sólo daría asilo político, sino que también se uniría a la causa republicana, siempre y cuando fuera a beneficio propio, en el arte del doble juego político ${ }^{20}$.

\footnotetext{
${ }^{17}$ Cai Shaoqing. "On the overseas Chinese secret societies of Australia", New Zealand Journal of Asian Studies 4, no. 1 (2002): 38.

${ }^{18}$ Gasster. "The republican", 470.

${ }^{19}$ Damon. "Financing Revolution", 168.

${ }^{20}$ Japón esgrimiría como uno de sus argumentos políticos y expansionistas: la "raza amarilla". Se consideraba defensor de la cultura asiática y estaba en contra de los ataques discriminatorios hacia los
} 
En 1902, Sun Yatsen realizó una nueva estrategia para obtener fondos y apoyar a la revolución ${ }^{21}$. Sun requería un proyecto nacional que fuera legitimo entre la comunidad china en el exterior, que propusiera un futuro colectivo y diera respuesta a las vicisitudes de ese momento histórico. En los chinos de ultramar no sólo buscaría la base financiera del proyecto, sino que promovería un nacionalismo vigoroso. Esta nueva estrategia quedaría sujeta al principio de corresponsabilidad. Estos principios aspirarían a forjar un nuevo ciudadano, como ente político-jurídico, en el reconocimiento a su contribución al país y creación de mecanismos de protección a estas comunidades, en efecto, a un nuevo curso de acción.

Como parte del movimiento revolucionario, Sun Yatsen tenía la intención de ir a los Estados Unidos para recaudar fondos y difundir sus ideas entre las comunidades chinas. En 1904, Sun viajó por todo los Estados Unidos. El Tongmenghui estadounidense se integraba de profesores, estudiantes y pequeños mercaderes. El apoyo de estos miembros le permitió a Sun viajar y correr con los gastos requeridos para su programa político. La fuente financiera principal fueron los fondos revolucionarios ${ }^{22}$.

Una parte de la estrategia financiera de Sun Yatsen fue la emisión de bonos con diferentes precios en distintos países, pero la idea básica era que un bono se vendiera a un precio fijo, determinado por Sun. A cambio, Sun Yatsen prometía su devolución con intereses cuando se estableciera la república. Sun ofrecía beneficios sustanciales, y esto creó el incentivo para comprar bonos ${ }^{23}$. A principios de 1911, Sun tenía bonos impresos en San Francisco en denominaciones de US\$10, US\$100 y US\$1000, con la esperanza de recaudar fondos para el levantamiento de Guangzhou. Después del establecimiento de la República los bonos debían ser moneda legal en China ${ }^{24}$.

Hubo varios tipos de beneficios para la causa. Uno de ellos era la promesa de honores especiales después del establecimiento de la república. Si donaba US\$100 la ciudadanía sería garantizada, si daba US $\$ 1000$ se le prometía preferencias comerciales, y si aportaba con US\$1 millón, se le erigiría una estatua como donante patriótico y algunos parques llevarían su nombre. Luego se organizó una oficina de recaudación de fondos con la ayuda de los líderes del Hongmen ${ }^{25}$. El viaje al continente americano dio pauta para un nuevo ciclo con los chinos de ultramar. En este sentido, las condiciones en la que estaba la China imperial cuando ellos salieron de su país y el escenario

asiáticos, argumentando que "los blancos han aplastado a los pueblos de Asia". Esta argumentación, finalmente justificaría sus acciones expansionistas en China reflejadas en las 21 demandas de 1915. Japón logró controlar la parte norte de China -Shandong, Mongolia Interior y Manchuria-, las provincias costeras del sureste y el valle del Yangtzé, así como los sistemas ferroviarios. En esta misma línea, en 1940, Tokio incluiyó la defensa de Asia mediante la Esfera de Coprosperidad de Asia para la formación de un bloque asiático contra la expansión e influencia europea. Es decir, desde la propuesta conceptual de geopolítica de Friedrich Ratzel, el Estado funciona como "un organismo vivo, y como tal, necesita espacio para crecer y moverse”. Jorge E. Atencio, ¿Qué es la geopolítica? (Buenos Aires: Pleamar, 1995), 15.

${ }^{21}$ Damon. "Financing Revolution", 168.

${ }^{22}$ Damon. "Financing Revolution", 170.

${ }^{23}$ Damon. "Financing Revolution", 171.

${ }^{24}$ Wilbur, Sun Yat-sen, 42.

${ }^{25}$ Wilbur, Sun Yat-sen, 43. 
internacional, eran distintas. Pero también, debemos tomar esta situación con un poco de cautela, porque en estos momentos, para esta comunidad el vínculo podría significar un nuevo ciclo o simplemente nuevas intenciones revolucionarias. La visita de Sun Yatsen a las redes fraternales en América fortaleció su proyecto nacional. No obstante, el crecimiento de ayuda financiera se enfrentó a grandes dificultades debido a la especulación del dinero y la poca certeza que había al comprar los bonos revolucionarios. Finalmente, este pragmatismo financiero ayudó a lograr a recabar fondos. La buena disposición de esta comunidad, reflejó que a ellos también les interesó fortalecer su relación con Sun debido a las promesas dadas y al aumento del racismo sufrido como extranjeros ${ }^{26}$.

En 1903, después de salir de Japón, Sun Yatsen viajó desde una comunidad china en el extranjero a otra para recaudar fondos, buscar adherentes y sondear el apoyo extranjero. En Hanoi, fundó una pequeña rama del Xingzhonghui y se reunió con las autoridades francesas para explorar la posibilidad de obtener ayuda ${ }^{27}$. Esta nueva coyuntura le ofreció a Sun la oportunidad de expandirse en otras comunidades de chinos y de obtener beneficios monetarios. La voz al llamado republicano se escuchaba mejor en estos territorios, mucho más apreciada, comprendida y también, porqué no, compartida con otras naciones.

En 1904, en los Estados Unidos, Sun Yatsen se unió al Hongmen. Su afiliación le ayudó a recaudar dinero suficiente para cubrir sus gastos de viaje. Recibió ayuda por parte de cristianos, tanto chinos como estadounidense y descendientes europeos. Sin embargo, los chinos de ultramar favorecían - moral y financieramente- a la Sociedad Protectora del Emperador Baohuanghui 保皇会 ${ }^{28}$ de Kang Youwei 康有為 (18581927) y Liang Qichao 梁啟超 (1873-1929) ${ }^{29}$. Estas redes fraternales y asociativas ya habían surgido en Estados Unidos antes de que Sun las conociera, debido a la discriminación contra los chinos y a la necesidad de protección y ayuda. Así como para defender sus intereses comerciales o asistenciales en asociaciones legalmente establecidas, muchos de ellos afiliándose a agrupaciones secretas como el Levantamiento Patriótico I Hing ${ }^{30}$. La preocupación de estas asociaciones surgió por el hecho de que el Imperio Qing no daba señales de respuestas enérgicas para la abolición de las leyes antichinas, este problema fue esencial para que en Estados Unidos creciera

\footnotetext{
${ }^{26}$ Además del tratado sino-estadounidense Burlingame de 1869, que estableció la protección mutua de sus ciudadanos y el derecho de residencia; en 1880 se aprobó el Tratado de Regulación de la Inmigración China, el cual normalizó la entrada o la residencia de los chinos en los Estados Unidos, y garantizó su protección ante hechos violentos. Por su parte, en 1982, se aprobó la Ley Geary en la que se suspendió la entrada de chinos a los Estados Unidos. Laverne M. Dicker, The Chinese in San Francisco: A Pictorial History (Nueva York: Dover Publications, 1979), 11-12.

${ }^{27}$ Gasster, "The republican", 473.

${ }^{28}$ Esta sociedad se formó durante el exilio de Kang Youwei y Liang Qichao en Victoria, Canadá en 1899, después del golpe de palacio dado por la emperatriz viuda Cixi. Su objetivo era que el emperador Guangxu nuevamente asumiera el poder.

${ }^{29}$ Gasster, "The republican", 486.

${ }^{30}$ Ryoichi Hisasue, "Vadeando el Pacífico. Las redes que tejieron las Kam-Shan-Chong de los huaqiao", trad.: Isami Romero Hoshino, Istor, Revista de historia internacional 27 (2006): 46-62.
} 
la ayuda hacia el proyecto republicano, ya que el problema migratorio para resolverse requería del reconocimiento de que las migraciones chinas fueron el resultado de un proceso de interacción de diversos factores propios del país de origen y del de destino. Por consiguiente, para lograr consensos entre estas comunidades también se requería a alguien con la sensibilidad y el conocimiento de las condiciones de vida de los chinos en el exterior, y Sun era la persona adecuada.

Desde 1905, las revistas y los folletos revolucionarios se propagaron por todo el mundo. La publicación líder fue el Informe Popular Minbao 民报, el diario oficial de la Alianza Revolucionaria. Tokio siguió siendo el centro de operaciones, pero las contribuciones provenían principalmente de Hong Kong, Singapur, París, San Francisco, Vancouver y Honolulu. A pesar de este apoyo otorgado, las sociedades secretas, los chinos de ultramar y los extranjeros parecieron haber sido una frágil coalición que proporcionara una base sólida a la revolución ${ }^{31}$. La estrategia de Sun Yatsen se limitaba geográficamente y socialmente por la configuración de las redes de influencia bajo su control. Las sociedades secretas, al final resultaron ser un activo operativo menor de lo previsto, a causa de su débil coherencia interna y la falta de fiabilidad de sus líderes. Sun Yatsen también podría contar con la generosidad de unos protectores ricos: empresarios y financistas de trabajo, ya sea por sí mismos o como intermediarios en la entrega de los subsidios pagados por algunos gobiernos extranjeros $^{32}$. Parecía que entre más se incrementaba su actividad internacional, más errores se cometían, al no tener una estrategia clara en su política. En este momento, Sun enfrenta la difícil tarea de fortalecer la base del apoyo revolucionario. Con la creación del Tongmenghui, se abriría una nueva etapa en su programa republicano.

\section{Segunda etapa: 1905-1911}

Para Glen Peterson, Sun Yatsen representó a los chinos en el extranjero como "huérfanos de ultramar" y se refería a ellos como la "madre de la revolución", gracias al dinero y a los esfuerzos que hicieron al programa republicano ${ }^{33}$. De 1894 hasta 1911, Sun viajó por muchos países defendiendo la causa revolucionaria y solicitando financiamiento para realizarla. Durante esta búsqueda, su creatividad y métodos para la recaudación de dinero se hicieron presentes durante sus viajes al exterior. De tal forma, que el dinero funcionó como un instrumento político para derrocar a la dinastía Qing ${ }^{34}$. Como resultado, el apoyo financiero quedó entrelazado a la propaganda política de Sun. La dispersión de los chinos de ultramar en distintos países, le forzaron a centrarse en la creación de mecanismos estratégicos para su unión y para poder promocionar la causa

\footnotetext{
${ }^{31}$ Gasster. "The republican", 474 y 491.

${ }^{32}$ Marie-Claire Bergère, Sun Yat-sen, trad.: Janet Lloyd (Stanford: Stanford University Press, 1994), 186191.

${ }^{33}$ Glen Peterson, Overseas Chinese in the People's Republic of China (Nueva York: Routledge, 2012), 6.

${ }^{34}$ Damon. "Financing Revolution", 163.
} 
republicana. Es por ende, que da importancia a las redes fraternales y asociativas de los chinos de ultramar. El vínculo dinámico entre Sun Yatsen y los chinos de ultramar ayudó a la creación y al impulso de nuevas organizaciones o redes de chinos en el extranjero con la tendencia de compartir intereses estratégicos en común en las siguientes décadas. Así, la comunidad de chinos de ultramar actuaría como un ente político y financiero para la promoción del proyecto nacional.

Desde un punto de vista político, la propaganda política de Sun Yatsen fomentó el nacionalismo, la democracia y la justicia social para la integración de los chinos de ultramar en su proyecto nacional por medio del amor hacia el país. Los que fueron, eran y querían, se plasmaba en el proyecto republicano. El nacionalismo era el elemento unificador que permitiría la creación de la identidad nacional y abriría las puertas para la participación política. Una de las condiciones para que este proceso político fuera sólido y exitoso es que existiera un proyecto nacional; uno que contara con la aceptación y el respaldo de las fuerzas políticas, y que no sólo fuera legítimo a ojos de la mayoría de la población. Cuestión que no sucedió, el establecimiento de la República no cambió la estructura política de siglos ni contrarrestó el poder de la élite china. Desde la óptica financiera, el vínculo se basó en la donación y los préstamos gracias a las redes fraternales y asociativas provenientes de pequeños comerciantes en distintos países. Para los chinos de ultramar sería el nexo para rescatar a su patria del dominio "extranjero" manchú y para "no dejar de ser chinos" 35.

Después de la formación de la Tongmenghui, los esfuerzos de recaudación de fondos por parte de ésta durante el período comprendido entre 1905 a 1912 fueron en aumento. Su principal y continua fuente de apoyo eran los chinos de ultramar, pero también fue el apoyo de algunos banqueros y gobiernos extranjeros que deseaban utilizar a Sun para su beneficio ${ }^{36}$, como sucedió en Francia, lugar donde prometió a sus líderes que si lo apoyaban con los recursos financieros tendrían derechos para la explotación de minas cuando la República se estableciera. Sin embargo, sólo fueron pocos los funcionarios franceses que le brindaron ayuda debido a que estaban más interesados en el control de Indochina. De tal manera, que el dinero se convertía en un instrumento político, al ser invertido lo usarían para ganar un mayor acceso a los recursos naturales de China y para ampliar sus beneficios económicos a mediano plazo.

Se estima que entre 1907 y 1911, Sun Yatsen recaudó HK\$600000. El dinero provenía de varias fuentes: las cotizaciones de los miembros de la Alianza Revolucionaria, las donaciones y los préstamos. La mayoría de los proveedores de fondos eran miembros de las comunidades chinas en el extranjero. La mayoría oficinistas, empleados y comerciantes de origen cantonés. Luego estaban los estudiantes chinos en Japón, Estados Unidos y Europa, los cristianos chinos, y los emigrantes de segunda generación que estudiaban y vivían en los Estados Unidos. Sun Yatsen les prometía renovar China y convertirla en una nación gloriosa, capaz de proteger a sus

\footnotetext{
${ }^{35}$ En el sentido de representarse como chino aunque fueran de la segunda generación en el extranjero.

${ }^{36}$ Wilbur, Sun Yat-sen, 39 y 42.
} 
emigrados $^{37}$. El proyecto republicano era la solución para los problemas de China. Con una gran ambición del futuro, parecía que la venta de los "bonos revolucionarios" le permitiría a Sun introducir cambios de forma y fondo a China. Este hecho, hacía ver que el proyecto republicano contenía cierta dosis de pensamiento utópico, pero no se alejaba de su utilidad como instrumento político.

Por otra parte, el desapego y la falta de interés del Imperio Qing para los chinos de ultramar, así como la tendencia del racismo chino en distintos países, pudo fomentar tanto el proyecto republicano como la influencia de los chinos del exterior en la política nacional. Esta participación financiera de la comunidad china al exterior iría consolidando poco a poco su integración en la vida política china. Claro está que no había un proyecto político para estas comunidades en su inserción al proyecto nacional, ni una definición de cómo a estos chinos de ultramar se les concedería los mismos derechos que los chinos continentales y su protección fuera del país, así como las formas para poder lograrlo. En ese entorno, lo urgente era sacar a los manchúes del poder y establecer la república. El expansionismo japonés y ruso también se convirtieron en otro argumento contundente contra el Imperio Qing. El discurso nacionalista como elemento de cohesión, hizo el llamado a pelear contra estos países. Japón y Rusia querían la hegemonía en Asia, por ello su competencia territorial y económica en China; mientras Gran Bretaña buscaba nuevos mercados para la venta de sus mercancías, así como de recursos naturales para su crecimiento industrial. En esta situación, Sun Yatsen intensificaría su participación dentro de estas comunidades, siguiendo una clara línea de defensa por la autodeterminación y la soberanía de China. No obstante, este nacionalismo se debe tomar con cautela, ya que consistió en la lucha contra la dinastía manchú y no contra las potencias, debido a la poca habilidad política para negociar con ellas. Sun tenía la esperanza de recibir ayuda del extranjero.

Durante los 16 años que Sun estuvo recaudando fondos para la revolución, los chinos de ultramar que vivían en el Sudeste Asiático se convirtieron en su más importante recurso, a pesar de que se le declaró persona non grata por los gobiernos asiáticos $^{38}$. Durante estos años, Sun fue a la Indochina francesa y emitió bonos por valor de US\$100000 para recaudar fondos para seis levantamientos militares ${ }^{39}$. La cooperación entre Sun y los chinos de ultramar difícilmente por si sóla podría garantizar el triunfo de los principios guías del nuevo Estado-nación -teoría de los Tres Principios del Pueblo y de los Cinco Poderes de Sun- ${ }^{40}$. Ésto sólo se explica mediante la voluntad política de Sun y de sus allegados, quienes con una gran habilidad de organización y ejecución, lograron sacar provecho de las comunidades chinas del exterior,

\footnotetext{
${ }^{37}$ Bergère. Sun Yat-sen, 190-191.

${ }^{38}$ Damon, "Financing Revolution", 176-177.

${ }^{39}$ Yansheng Ma Lum y Raymond Mun Kong Lum, Sun Yat-Sen in Hawaii: Activities and Supporters (Honolulu: University of Hawaii Press, 1999), 46.

${ }^{40}$ Los tres principios eran nacionalismo, democracia y bienestar del pueblo. El nacionalismo era antimanchú, la democracia se concebía relacionada con la igualdad de derechos de todos los ciudadanos y el bienestar del pueblo se asociaba con los beneficios que traerían la industrialización y el comercio en las zonas urbanas. Para lograrlo, se erigirían cinco poderes: el ejecutivo, el legislativo, el judicial, el educativo y el censorado.
} 
principalmente de las redes fraternales que surgieron y adoptaron en su entorno el programa republicano.

Después de ser expulsado de Japón en 1907 y de Hanoi en 1908, Sun se refugió en Singapur. Desde allí reanudó sus viajes a las comunidades chinas de todo el mundo ${ }^{41}$. Singapur era una zona clave porque ya habían establecidas sociedades secretas chinas. La sociedad conocida como la Tríada - principalmente de las provincias de Guangdong y Fujian-, en el siglo XIX tuvo un papel importante en las relaciones políticas entre la sociedad y el Estado. Los migrantes del Sudeste de Asia llevaron estas sociedades al extranjero, como un medio para discutir temas de interés en su comunidad. Singapur, como centro regional, fue el escenario de las reuniones de la sociedad secreta ${ }^{42}$.

Para 1906, en Singapur, Sun creó una rama del Tongmenghui, seguido por otras en Malasia, abriendo un período de intensa y despiadada lucha entre revolucionarios y reformistas. Se buscó hacer un uso efectivo de nuevos métodos de movilización política, organización, adoctrinamiento, propaganda, mítines de masas y la búsqueda por el control de las organizaciones sociales. Para Sun, Singapur y Malasia eran importantes por tres cosas: una fuente de fondos, mano de obra y una base revolucionaria estratégica por su cercanía con China ${ }^{43}$. En un primer momento, Sun contó con el apoyo de los principales comerciantes o de sus hijos ${ }^{44}$. En noviembre de 1910, Sun se reunió con sus seguidores más cercanos en Penang, Malasia para planear otro levantamiento en Guangzhou. En éste se planeaba recaudar HK\$130000 entre los chinos de ultramar en el Sudeste Asiático ${ }^{45}$. Por su posición estratégica, Singapur y Malasia desempeñaron un papel importante para la intención de expandir su proyecto político en otras áreas del Sudeste Asiático, al tiempo que le permitió tener más contacto con el territorio chino.

Cuando estalló la revuelta en Wuchang en octubre de $1911^{46}$, Sun estaba de gira en Chicago, Nueva York, Londres, París, Penang y Singapur, recaudando dinero para su campaña. Durante esta gira, los estudiantes chinos en Japón, Estados Unidos y Europa, contribuyeron con pequeñas cantidades de dinero. Otro grupo que siguió apoyando a Sun fueron los cristianos chinos, muchos de ellos ya tenían bastante tiempo viviendo en los Estados Unidos, o bien, eran de segunda generación ${ }^{47}$. Sun distinguía la función de determinados grupos sociales: las sociedades secretas participaban del levantamiento

\footnotetext{
${ }^{41}$ Gasster. "The republican", 506.

${ }^{42}$ Maurice Freedman, "Immigrants and Associations: Chinese in Nineteenth-Century Singapore", Comparative Studies in Society and History 3, no. 1 (1960): 10 y 30.

${ }^{43}$ Yen Ching-Hwang, "The Overseas Chinese and the 1911 Revolution. With Special Reference to Singapore and Malaya", Pacific Affairs 51, no. 4 (1978-1979): 202.

${ }^{44}$ Bergère, Sun Yat-sen, 192.

${ }^{45}$ Wilbur, Sun Yat-sen, 45.

${ }^{46}$ Tras la explosión de una bomba en Hankou, la policía descubrió que los revolucionarios y las sociedades secretas estaban en complot contra el Imperio Qing. Ante esto, los conspiradores hicieron un llamado de levantamiento armado contra la dinastía, a ella se unieron el octavo Batallón de Ingenieros de Wuchang y las unidades de transporte y artillería el 10 de octubre de 1911.

${ }^{47}$ Wilbur, Sun Yat-sen, 45-46.
} 
armado, los intelectuales delineaban las directrices para el establecimiento del régimen republicano y los comerciantes chinos de ultramar aportaban el dinero necesario para el proyecto republicano $^{48}$.

Los chinos de ultramar eran los más enfadados por la falta de respuesta del Imperio Qing ante la discriminación que sufrían en Hong Kong, Singapur, Hanoi y San Francisco $^{49}$. De este modo, los revolucionarios y la Sociedad de la Triada recurrieron al discurso patriótico al no desvincularse de la "madre patria" y expulsar a los "bárbaros". El discurso patriótico hizo énfasis a la promesa de una gloriosa y moderna China de la cual podrían estar orgullosos. Para los emigrantes, este llamado era atractivo, puesto que ya no querían a sus comunidades inmersas en la pobreza, situación que ellos padecieron $\mathrm{y}$ por la cual emigraron de sus tierras ${ }^{50}$. Incluso, este discurso tuvo mayor aprobación entre los chinos de ultramar que en las élites locales chinas ${ }^{51}$. Por medio de la exaltación del "amor a la patria" y a la etnia frente a los manchúes, Sun buscaba que los chinos de ultramar no olvidaran su identidad china.

Hasta 1909, el Baohuanghui de Kang Youwei tuvo influencia entre los chinos de ultramar. Pero cada vez más los revolucionarios tuvieron mayor influencia en los periódicos, más poder en el Hongmen y más ayuda de los chinos ricos de ultramar. A su vez, la habilidad y el carisma de Sun ayudó a que su proyecto se fuera fortaleciendo con el paso del tiempo ${ }^{52}$. Sus experiencias en el extranjero le ayudaron a ganarse la confianza de estas comunidades. Era consciente de las condiciones de vida en la que estaban. Su política activa logró consensos y buscó estrategias en las que pudieran integrarse los chinos de ultramar en el apoyo a su proyecto político. Era un hombre hábil y persistente, y con una gran imaginación cuando se trataba de ganar adeptos.

Las fuentes más importantes de los fondos eran las contribuciones y los préstamos. Los bonos eran pagarés que después de establecido el gobierno republicano serían devueltos al comprador a un precio mayor de su inversión original. Acorde con las investigaciones de Shelley Hsien Cheng, durante el periodo comprendido entre octubre de 1911 y julio de 1912, es decir, en el momento del levantamiento armado en Wuchang, el Tongmenghui pudo recaudar HK\$2380000 en el extranjero por medio de los fondos de ayuda, las donaciones, la venta de bonos y los préstamos ${ }^{53}$.

Como resultado de los esfuerzos de recaudación de fondos entre 1900 y 1911, Sun recibió por medio de las sociedades secretas, aproximadamente US\$97500 desde los Estados Unidos y Canadá. Dispersos a lo largo y ancho del mundo, cada fraternidad llevó su estructura en términos geográficos e históricos ${ }^{54}$.

\footnotetext{
${ }^{48}$ Bergère, Sun Yat-sen, 193.

${ }^{49}$ Gasster. "The republican", 483.

${ }^{50}$ Wilbur, Sun Yat-sen, 46-47.

${ }^{51}$ Bergère, Sun Yat-sen, 193.

${ }^{52}$ Wilbur, Sun Yat-sen, 46-47.

${ }^{53}$ Wilbur, Sun Yat-sen, 41-42 y 49.

${ }^{54}$ Floyd Cheun, "Performing Exclusion and Resistance: Anti-Chinese League and Chee Kung Tong Parades in Territorial Arizona", TDR 46, no. 1 (2002): 54.
} 
En los Estados Unidos, Sun Yatsen aprovechó el creciente sentimiento nacionalista entre los chinos de ultramar en territorio estadounidense debido a la falta de una respuesta firme del gobierno Qing a los problemas de racismo que pasaban. Sun visitó los lugares donde estaba establecida la comunidad china. En estos viajes, fue recibido por las logias locales del Zhigongtang ${ }^{55}$.

Ante el poco apoyo moral y financiero al Tongmenghui, en junio de 1911, Sun fusionó el Tongmenghui con el Zhigongtang para conseguir el apoyo de los líderes de éste último. Aunque, estas asociaciones tenían distintos objetivos políticos, para los líderes del Zhigongtang la fusión significaba obtener el reconocimiento y la legitimidad de su organización en China. La Gran Logia del Zhigongtang se encontraba en San Francisco, ciudad donde se organizó en $1853^{56}$.

En este sentido, históricamente, el Zhigongtang era una rama de la Sociedad Secreta de la Tríada fundada para derrocar al gobierno manchú y restaurar el dominio han $^{57}$. Sin embargo, esta sociedad tuvo características distintas en el lugar donde se estableció. A manera de ejemplo, en California, el Zhigongtang degeneró en actividades criminales, compitiendo con otras sociedades para controlar la prostitución y el juego ${ }^{58}$. En Vancouver, la organización estaba integrada por trabajadores migrantes, tenderos y pequeños comerciantes. A partir de la tradición de la hermandad y las sociedades secretas que prevalecen en la parte volátil y frontera de la costa sur de China, el Zhigongtang exaltaba la lealtad de grupo, la confianza mutua y otras formas de comportamiento virtuoso ${ }^{59}$.

En 1900, para el Partido Reformista de Kang Youwei y el Partido Revolucionario de Sun Yatsen, el Zhigongtang significó un ente de ayuda para sus proyectos políticos. El principal problema para los líderes del Zhigongtang era quién y qué tipo de gobierno chino apoyar. Algunos líderes del Zhigongtang sintieron que Sun Yatsen era demasiado radical, mientras otros creían en sus ideales de inspiración liberal. Originalmente, esta asociación apoyaba a Kan Youwei, no obstante, cuando Sun Yatsen empezó a ganar más popularidad, esta sociedad lo empezó a ayudar. El Zhigongtang no

\footnotetext{
${ }^{55}$ Los orígenes de esta sociedad se hallan en las provincias sureñas de Taiwán, Fujian, Guangdong y Guangxi en el en el siglo XVII, después de la caída de la dinastía Ming y el inicio de la dinastía Qing. El Zhigongtang en Estados Unidos surge como la "sociedad masónica china" en San Francisco en 1849. Debido al incremento de racismo antichino, su objetivo a finales del siglo XIX e inicios del XX, era la defensa de la comunidad china. Esta sociedad se expandió por varios países americanos: Estados Unidos, Canadá, México, Cuba y Perú. María Teresa Montes de Oca Choy y Yasmín Ydoy Ortiz, "Chee Kung Tong ¿Vínculos masónicos?”, REHMLAC 1, no. 1 (2009): 238- 241 [citado el 15 de noviembre de 2014]: disponible en http://www.rehmlac.com/recursos/vols/v1/n1/rehmlac.vol1.n1-mmontesdeocayyydoy.pdf

${ }^{56}$ Shehong Chen, Being Chinese, Becoming Chinese American (Urbana: University of Illinois Press, 2002), 37.

${ }^{57}$ Philip P. Choy, San Francisco Chinatown: A Guide to Its History and Architecture (San Francisco: City Lights Books, 2012).

${ }_{58}^{58}$ Choy, San Francisco Chinatown.

${ }^{59}$ Wing Chung Ng, The Chinese in Vancouver, 1945-80: The Pursuit of Identity and Power (Vancouver: UBC Press, 1999), 13.
} 
sólo brindaría ayuda económica, sino también propagandística como el periódico Chinese Free Press, a favor de la causa revolucionaria ${ }^{60}$.

En abril de 1904, Sun hizo su segunda gira de recaudación de fondos en los Estados Unidos. Wong San-duck, presidente del Zhigongtang, lo acompañó durante su gira por todo los Estados Unidos, presentándoles a los miembros Zhigongtang. Ya en este mismo año, Sun se unió al Zhigongtang en Honolulu, y el apoyo de la sociedad jugó un papel importante en el éxito de sus actividades revolucionarias ${ }^{61}$.

Empero, el apoyo por parte de los chinos en los Estados Unidos no se logró fácilmente. La élite de la comunidad china en los Estados Unidos aún estaba ligada al gobierno Qing. La Asociación China de Beneficencia Consolidada (CCBA por sus siglas en inglés) y la Cámara de Comercio de China aún trabajaban estrechamente con el cuerpo diplomático del Imperio Qing en los Estados Unidos, su poder y posición dependía del mantenimiento del sistema y gobierno existente en China ${ }^{62}$.

Tras la fusión del Tongmenghui con el Zhigongtang, la Oficina Nacional de Socorro se organizó en los Estados Unidos para recaudar dinero para la causa revolucionaria de Sun Yatsen. La Gran Logia del Zhigongtang en San Francisco hizo propaganda entre los chinos de ultramar y dieron discursos a favor del establecimiento del proyecto republicano. Estas acciones tuvieron respuesta positivas entre la comunidad china; en la cual, se recaudó dinero, se establecieron albergues y se colectaron víveres para los líderes. Es importante señalar que la mayor parte de esta comunidad en los Estados Unidos tenía parte o gran parte de sus familias en China ${ }^{63}$.

Con el levantamiento de Wuchang del 10 de octubre 1911, la atmósfera política en las comunidades chinas en los Estados Unidos cambió. Los periódicos como el Zhongxi Ribao 中西日报 y El Mundo chino difundieron la causa revolucionaria. En Chicago, Los Ángeles, Nueva York y otras ciudades estadounidenses se vendieron los bonos emitidos por la Oficina Nacional de Socorro ${ }^{64}$.

El descontento entre los trabajadores del Barrio Chino por la falta de compromiso real del gobierno Qing y la red que se formó entre los restauranteros, chinos cristianos y mujeres, recaudaron grandes cantidades de dinero, contribuyeron a una mayor presión hacia el CCBA y la Cámara de Comercio de China en los Estados Unidos, y para finales de 1911, reconocieron a Sun Yatsen como el primer presidente de la República de China ${ }^{65}$.

No obstante, la alianza entre el Tongmenghui y el Zhigongtang duró poco, principalmente por dos causas. Primero, después de la fundación de la república, los líderes del Tongmenghui no reconocieron el papel del Zhigongtang en la fundación de la República de China. De hecho, de los US\$300000 que Sun Yatsen recaudó durante la

\footnotetext{
${ }^{60}$ Choy. San Francisco Chinatown.

${ }^{61}$ Yansheng Ma Lum y Raymond Mun Kong Lum, Sun Yat-Sen in Hawaii: Activities and Supporters (Honolulu, University of Hawaii Press, 1999), 30.

${ }^{62}$ Chen, Being Chinese, 38.

${ }^{63}$ Chen, Being Chinese, 37.

${ }^{64}$ Chen, Being Chinese, 38-39.

${ }^{65}$ Chen, Being Chinese, 39.
} 
instrumentalización de la "diplomacia del viajero" en los Estados Unidos, sólo Low Wing, líder del Zhigongtang, donó US\$3500 a Sun durante su visita a Winnemucca, Nevada. Segundo, cuando Yuan Shikai 袁世凱 (1859-1916) ascendió al poder presidencial entre 1912 y 1916, llevó a un conflicto dentro de la organización a nivel nacional e internacional. Esto contribuyó a una disminución de la afiliación y mermó el prestigio de la asociación ${ }^{66}$.

Las características del Tongmenghui y el Zhigongtang muestran que las asociaciones chinas de ultramar fueron heterogéneas. En ellas se observan dos vertientes. En primer lugar, las asociaciones que en un nivel menor de organización expresaban una relación cultural, económica y política. $\mathrm{Y}$ en segundo lugar, las asociaciones que actuaban en el marco de una sociedad secreta -con normas, rituales, con mayor grado de organización y fines claros-, tanto para hacer frente a los problemas externos que pasaba la comunidad en determinado país como para buscar un vínculo más estrecho a los problemas que aquejaban a su nación.

Finalmente, tras la Revolución de 1911 y el establecimiento de la República de China, las provisiones que dieron los chinos de ultramar, se reflejaron legítima y legalmente en el nuevo gobierno. De esta manera, en la Asamblea Nacional que se promulgó en 1912, seis de los 274 senadores debían ser chinos de ultramar ${ }^{67}$. El financiamiento tuvo consecuencias políticas. El discurso revolucionario de Sun generó entre los chinos de ultramar una interacción fluida y organizativa entre comunidades. Esta interacción encontró un eco político ante las demandas de estos grupos al ser reconocidos como entes legales, y no como personas de segunda. Debido al contacto con las ideas liberales, los chinos de ultramar exigieron su participación como actores con poder político y económico, así como el establecimiento formal y legal de su relación con las instituciones creadas por el gobierno revolucionario, en razón de ser inherentes al desarrollo del Estado. Su participación política en los asuntos del país aumentaría acorde con la coyuntura. Por ello, el convencerles mediante el discurso nacionalista se volvió una necesidad en la estrategia de Sun Yatsen y sus colegas en la recaudación monetaria, y una puerta abierta para que esta comunidad planteara sus demandas. El reconocimiento de su colaboración en el programa republicano, significó el rompimiento de la concepción que se percibía de ellos en China continental.

\section{Consideraciones finales}

Este trabajo explica la importancia de las redes fraternales y asociativas de los chinos de ultramar para el proyecto de República de Sun Yatsen. Hay argumentos políticos y comerciales para justificar y entender la importancia de estos actores en el programa republicano.

\footnotetext{
${ }^{66}$ Susie Lan Cassel, The Chinese in America: A History from Gold Mountain to the New Millennium (Walnut Creek, CA: Altamira Press, 2002), 227.

${ }^{67}$ Peterson. Overseas Chinese, 16.
} 
El activismo de Sun Yatsen fue circunstancial. Su exilio a Hawái le permitió crear una base para la expansión de su proyecto y apoyo financiero, y como resultado, construir una red global entre los chinos de ultramar para el logro de sus objetivos. En este sentido, esta comunidad se integró a los acontecimientos políticos de su país de forma indirecta. El apoyo ganado a la causa revolucionaria no se puede prescindir del esfuerzo político de Sun y sus allegados. El beneficio otorgado a los chinos de ultramar que apoyaran a la causa no se puede sujetar únicamente al análisis económico, sino en algo más profundo, en el reconocimiento como ciudadanos, como entes políticojurídicos.

El financiamiento y el apoyo nacionalista que tuvo el proyecto republicano de Sun para impulsar la construcción de la nación, sembró las simientes que permitieron entrelazar la conciencia nacional y el impulso de cambiar la estructura socio-económica del país. Por lo tanto, el reconocimiento de la contribución de los chinos de ultramar y la revolución republicana al exterior, marcaron la pauta para el proceso de transformación de China en un Estado-nación durante el siglo XX. Mientras tanto, los líderes revolucionarios transmitieron dentro y fuera del país la voluntad de que China se insertara en el nuevo escenario internacional.

¿Qué tan profunda sería la relación de los chinos de ultramar con el nuevo gobierno republicano? ¿Cuánto valdría para el presidente Sun Yatsen, y más aún, para China, el apoyo político y financiero de estas comunidades -que salieron huyendo de un gobierno que no les garantizó un nivel de vida digna- en un mediano y largo plazo? ¿Qué papel tendrían las redes fraternales en la política china después del establecimiento de la nueva república? ¿De qué forma integrarlos? Responder a esto requeriría de un proyecto nacional integral que estableciera mecanismos institucionales y jurídicos para la protección de los intereses de los chinos de ultramar. Hasta el ocaso del Imperio Qing, con el establecimiento de embajadas y consulados, se intentó proteger a la comunidad china en el exterior. La República de Sun legalizó y reconoció su participación política otorgándoles seis asientos en la Asamblea Nacional. Pero con el arribo a la presidencia de Yuan Shikai (1912-1916) y el escenario de preguerra mundial, la falta de un proyecto político conjunto y la poca compatibilidad de los intereses de las fuerzas políticas y el centralismo de su poder, hicieron que esta comunidad se viera excluida.

La revolución no rompió la estructura tradicional y la vieja clase dirigente mantuvo sus privilegios. En la economía no hubo un despegue de la producción y tampoco aumentó el bienestar social, la agricultura siguió siendo la actividad económica del país más importante, pero no se insertaron los avances tecnológicos ni las reformas agrarias requeridas. El poder provincial mantuvo el control de sus territorios, en cuyos ejércitos personales se integraron miembros del Tongmenghui gracias al descontento generalizado en el país. Por estos factores, el proyecto republicano no se consolidó ni fomentó la participación política de los chinos de ultramar.

Tras el análisis de la relación de Sun Yatsen con los chinos de ultramar surgen una serie de interrogantes relacionadas con la incorporación de China en el escenario 
internacional. Luego del establecimiento de la República se crearon mecanismos para la protección de los intereses de los chinos de ultramar, pero no se fomentó su integración a la vida política del país, ¿dejó de existir un vínculo dinámico entre estas redes, sin mayores pretensiones, o sólo se buscaron como entes estratégicos cuando se les requirió? Y acerca de los vínculos políticos con las redes fraternales y asociativas, ¿potenciaron el reto de la ahora República de China de insertarse al nuevo orden global? Son algunas de las problemáticas pendientes para próximas investigaciones.

\section{Bibliografía}

Atencio, Jorge E. ¿Qué es la geopolítica? Buenos Aires: Pleamar, 1995.

Bergère, Marie-Claire. Sun Yat-sen. Traducido por Janet Lloyd. Stanford, CA: Stanford University Press, 1994.

Cai Shaoqing. "On the overseas Chinese secret societies of Australia". New Zealand Journal of Asian Studies 4, no. 1 (2002): 30-45.

Cassel, Susie Lan. The Chinese in America: A History from Gold Mountain to the New Millennium. Walnut Creek, CA: Altamira Press, 2002.

Cheun, Floyd. "Performing Exclusion and Resistance: Anti-Chinese League and Chee Kung Tong Parades in Territorial Arizona". TDR 46, no. 1 (2002): 39-59.

Ching-hwang, Yen. "The Overseas Chinese and the 1911 Revolution. With Special Reference to Singapore and Malaya”. Pacific Affairs 51, no. 4 (1978-1979): 139140.

Chow Tse-tung. The May 4th Movement: Intellectual Revolution in Modern China (Harvard East Asian). Cambridge, MA: Harvard University Press, 1960.

Choy, María Teresa Montes de Oca y Yasmín Ydoy Ortiz. "Chee Kung Tong ¿Vínculos masónicos?”. REHMLAC 1, no. 1 (2009): 234-246. Disponible en http://www.rehmlac.com/recursos/vols/v1/n1/rehmlac.vol1.n1mmontesdeocayyydoy.pdf

Choy, Philip P. San Francisco Chinatown: A Guide to Its History and Architecture. San Francisco, Estados Unidos, City Lights Books, 2012.

Damon, Allen. F. "Financing Revolution: Sun Yat-sen and the Overthrow of the Ch'ing Dynasty". The Hawaiian Journal of History 25 (1991): 161-186.

Dicker, Laverne M. The Chinese in San Francisco: A Pictorial History. Nueva York: Dover Publications, 1979.

Feuerwerker, Albert. "Aspects of the Transition from Qing to Republican China". Republican China X, no. 2 (1985): 1-22.

Freedman, Maurice. "Immigrants and Associations: Chinese in Nineteenth-Century Singapore". Comparative Studies in Society and History 3, no. 1 (1960): 25-48.

Gasster, Michael. "The republican revolutionary movement". En The Cambridge History of China, editado por J. King Fairbank. Cambridge: Cambridge University Press, 1980. 
Gernet, Jacques. El Mundo Chino. Traducido por Dolors Folch. Barcelona: Editorial Crítica, 2005.

Hisasue, Ryoichi. "Vadeando el Pacífico. Las redes que tejieron las Kam-Shan-Chong de los huaqiao". Traducido por Isami Romero Hoshino. Istor, Revista de historia internacional 27 (2006): 46-62.

Lum, Yansheng Ma y Raymond Mun Kong Lum. Sun Yat-Sen in Hawaii: Activities and Supporters. Honolulu: University of Hawaii Press, 1999.

Murray, Dian y Qin Baoqi. The Origins of the Tiandihui. The Chinese Triads in Legend and History. Stanford, CA: Stanford University Press, 1994.

Peterson, Glen. Overseas Chinese in the People's Republic of China. Nueva York: Routledge, 2012.

Sánchez Solano, Esteban. "China y su primera experiencia en la modernidad política (1911-1927)". En Estudios sobre China desde Latinoamérica: Geopolítica, Religión e Inmigración. Editado por Susan Chen Mok, Jorge Bartels Villanueva, Ricardo Martínez Esquivel. San José, Costa Rica: SIEDIN - Universidad de Costa Rica, 2013.

Shehong, Chen. Being Chinese, Becoming Chinese American. Urbana: University of Illinois Press, 2002.

Tikhvinsky, S. L. Modern History of China. Traducido por Vic Schneierson. Moscow: Progress publishers, 1983.

Wilbur, C. Martin. Sun Yat-sen: Frustrated patriot. Nueva York: Columbia University Press, 1976.

Wing, Chung Ng. The Chinese in Vancouver, 1945-80: The Pursuit of Identity and Power. Vancouver: UBC Press, 1999.

Young, Ernest P. "Politics in the aftermath of revolution: the era of Yuan Shih-k'ai, 1912-1916”. En The Cambridge History of China, editado por J. King Fairbank. Cambridge: Cambridge University Press, 1980. 